\title{
Combined Effect of Daily Physical Activity and Social Relationships on Sleep Disorder Among Older Adults: A Cross-Sectional Study Based on Data From The Kasama Study
}

Jaehoon Seol ( $\nabla$ seol.jaehoon.ge@u.tsukuba.ac.jp )

University of Tsukuba

Jaehee Lee

University of Tsukuba

Koki Nagata

University of Tsukuba

Yuya Fujii

University of Tsukuba

Kaya Joho

University of Tsukuba

Korin Tateoka

University of Tsukuba

Taiki Inoue

University of Tsukuba

Jue Liu

University of Tsukuba

Tomohiro Okura

University of Tsukuba

Research Article

Keywords: insomnia, inactive, social isolation, exercise, depression

Posted Date: January 23rd, 2021

DOI: https://doi.org/10.21203/rs.3.rs-152102/v1

License: @ (1) This work is licensed under a Creative Commons Attribution 4.0 International License. Read Full License 


\section{Abstract}

Background: This cross-sectional study investigated whether the daily physical activity of older adults, combined with social relationships, is associated with the risk of sleep disorder. Further, it determined whether a high level of one variable with a low level of the other leads to a significantly lower risk of sleep disorder than low levels of both.

Methods: The sample comprised 988 community-dwelling older Japanese adults (mean age: $73.1 \pm 5.5$ years). The level of daily physical activity and range of social relationships were assessed using the Physical Activity Scale for the Elderly and the Lubben Social Network Scale, respectively. The Pittsburgh Sleep Quality Index was used to assess sleep disorder. To test linear trends and the combined effect of the two variables, both variable values were divided into tertiles. To test the combined effects, medians were calculated for the respective scores, based on which the participants were categorized into the following groups: (1) inactive with a narrow range of social relationships ( $n=307),(2)$ inactive with a wide range of social relationships ( $n=183)$, (3) active with a narrow range of social relationships $(n=205)$, and (4) active with a wide range of social relationships $(n=293)$. After adjusting for potential confounders, a logistic regression analysis was conducted.

Results: Participants who were more physically active (odds ratio [OR]: 0.694, 95\% confidence interval [Cl]: 0.484-0.997) and those with a wide range of social relationships (OR: $0.690,95 \% \mathrm{Cl}: 0.481-0.988$ ) showed a lower prevalence of sleep disorder than those in the first tertile; these effects were independent of each other. The combined effect analysis revealed that the active group with a wide range of social relationships showed a significantly lower prevalence of sleep disorder (OR: $0.585,95 \% \mathrm{Cl}: 0.404-0.847)$ than the inactive group with a narrow range of social relationships.

Conclusions: Our findings suggest that being physically active with a wide range of social relationships is favorably associated with sleep quality. However, a high level of one variable with a low level of the other is inefficient in improving sleep quality among older adults.

\section{Background}

Sleep disorder is common in later life, and various epidemiological studies have reported that it affects $36-70 \%$ of community-dwelling older adults [1, 2]. The prevalence of sleep disorders increases dramatically as people reach later life [3], and sleep disorders are strongly linked to risks of mortality, falls, cognitive impairment, and depression [4-7].

The American Geriatrics Society recommends the use of nonpharmacological tools to improve sleep quality [8]. Exercise is a representative nonpharmacological intervention, and high levels of daily physical activity have been found to be associated with a lower prevalence of sleep disorder in older adults; however, the effects of exercise in this regard depend on the intensity, duration, and time of day at which it is performed [9-11]. In addition, some epidemiological studies have suggested that high levels of housework and/or work-related activities are associated with a lower prevalence of sleep disorder $[12,13]$. These studies suggest that, similar to exercise, housework and/or work-related activities are positively associated with thermoregulation and/or regulation of the circadian system, which consequently improves sleep quality in older adults $[12,13]$. Physical activity, including exercise, is a free or low-cost method of promoting health benefits, especially physical and cognitive function, mood, and sleep, and has a low risk of side effects in older adults [14]. Sleep disorder is associated with poorer physical function in older adults $[15,16]$; however, the mechanism by which disturbed sleep impacts physical function is currently unknown. It is possible that the relationship between physical activity and sleep quality is mediated by physical function [16].

Previous studies have found that a narrow range of social relationships is associated with an increased risk of mortality [17-19]; this is because long-term social isolation can create chronic stress [17]. Conversely, some epidemiological studies have reported that a wide range of positive social relationships (e.g., supportive ties) is related to lower prevalence of sleep disorder $[20,21]$. An epidemiological study revealed that older adults who have a high number of positive social relationships for at least 15 years have better sleep quality than those with shorter-duration relationships [21]. Furthermore, combining 
low-intensity physical activity with social interaction has been found to increase the prevalence of slow-wave sleep (i.e., deep sleep) and improve cognitive function among older adults [22]. In later life, older adults naturally have fewer social relationships (e.g., as a result of retirement, bereavement); the above findings suggest that older adults should seek to counteract this by endeavoring to maintain or expand their range of social relationships, as this is an important factor for their quality of life.

Physical activity and social relationships are, for older adults, positively related to not only physical and cognitive functions and mental health but also sleep quality. Both of these variables are positively correlated [23]; however, previous research has scarcely considered the confounding factors for each of these variables $[9,10,20]$. Furthermore, some older adults lack either social relationships or physical activity, or both. Considering this finding and previous results, we hypothesized that the prevalence of sleep disorder is lower among people with a low level of one of these variables (i.e., social relationships or physical activity) and a high level of the other, compared to those who are inactive and have a narrow range of social relationships. Thus, to identify the relationship between sleep quality and a high level of one of these variables plus a low level of the other, we examined the combined effect of physical activity and social relationships on the prevalence of sleep disorder among community-dwelling older adults in Japan.

\section{Materials And Methods}

\section{Participants and Data Collection}

This cross-sectional study was based on data from the Kasama Study, which was a community-based cohort study conducted in Japan between 2011 and 2019 [24]. Participants for each year of the study were randomly selected from the Basic Resident Register using the following eligibility criteria: 1) aged 65 years or older, 2) not a recipient of long-term care insurance, and 3) living in Kasama City, Japan. A total of 1,094 community-dwelling older adults participated in this study, of whom 106 (9.7\%) were excluded because of incomplete data. Ultimately, 988 participants were included in the analysis.

\section{Daily Physical Activity}

The Japanese version of the Physical Activity Scale for the Elderly (PASE) [25] was used to assess participants' daily physical activity. The PASE is a 12-item questionnaire that measures the average hours per day spent performing leisuretime, housework, and work-related physical activity, respectively, over the previous seven days. Leisure-time physical activity includes walking; light-, moderate-, and vigorous-intensity recreational activities; and muscle-strength training. Housework includes light and heavy housework, home repair, lawn work or yard care, outdoor gardening, and caring for other people. Finally, work-related physical activity includes paid and volunteer work. These items are weighted based on the intensity of each activity, and the total PASE score is the sum of the 12 weighted items [25]. For the present research, we used the PASE score to determine the participants' overall physical activity levels.

\section{Social Relationships}

To assess social relationships, we used the Japanese version of the Lubben Social Network Scale-6 (LSNS) [26]. The LSNS assesses social relationships through measuring the strength of respondents' family ties and friendship ties, respectively, in terms of each of the following three categories: 1) "How many people do you see or hear from at least once a month?" 2) "How many people do you feel sufficiently at ease with such that you can talk with them about private matters?" 3) "How many people do you feel sufficiently close to such that you could call on them for help?" All questions were answered using a six-point Likert scale: 0 = "none," 1 = "one," 2 = "two," 3 = "three or four," 4 = "five through eight," and 5 = "nine or more". The LSNS score was determined by summing the scores for all six items (thus, it ranges from 0 to 30) [26].

\section{Sleep Disorder}

We used the Pittsburgh Sleep Quality Index (PSQI) to identify sleep disorder; this tool has been used in both clinical research and epidemiological studies [27]. The PSQI measures seven components: subjective sleep satisfaction, sleep efficiency, 
sleep onset latency, sleep duration, sleep disturbances, use of sleeping medication, and daytime dysfunction. The score for each component is weighted by 0 to 3 , and the PSQI global score is determined by summing all items (thus, it ranges from 0 to 21 ). A previous study revealed that, with a cut-off of $5 / 6$, the PSQI global score has a sensitivity of $89.6 \%$ and a specificity of $86.5 \%$ for identifying cases of sleep disorder [27].

\section{Potential Confounders}

To identify potential confounders, we referenced previous studies [28] and included measures of age, sex, and body mass index (BMI); use of hypertension, psychotropic, diabetes, and sleep medication, respectively (respondents answered "yes" or "no" for all); medical history of lower back pain, knee pain, and hip pain, respectively ("yes" or "no" for all); alcohol consumption ("drinker" or "non-drinker"); tobacco-smoking status ("current" or "previous/never"); and presence of depressive syndrome (assessed using the Japanese version of the 15-item Geriatric Depression Scale (GDS) [29]).

\section{Statistical Analysis}

Linear trends in the prevalence of sleep disorder were computed using ordinal scoring for the PASE and LSNS scores, respectively [30]. For both scales, scores were divided into tertiles; for the PASE score, 0-94.3 points $(n=329)$ represented the "first tertile"; $94.5-140.4$ points $(n=329)$ represented the "second tertile"; and 140.6-462.3 points $(n=330)$ represented the "third tertile"; meanwhile, for the LSNS score 1-15 points $(n=351)$ represented the "first tertile"; $16-19$ points $(n=312)$ represented the "second tertile"; and 20-30 points $(n=325)$ represented the "third tertile." Additionally, to test the combined effects of the two factors, medians were calculated for the respective scores, and these were used to develop the following participant groups: (1) inactive with a narrow range of social relationships ( $n=307)$; (2) inactive with a wide range of social relationships ( $n=183)$; (3) active with a narrow range of social relationships $(n=205)$; and (4) active with a wide range of social relationships $(n=293)$.

To compare the four groups, we used one-way analyses of variance with Bonferroni post-hoc tests for continuous variables and chi-square tests for categorical variables. We used logistic regression analysis to examine the effect of physical activity and social relationships, individually and in combination with each other, on the prevalence of sleep disorder. First, in the tests of linear trends, we adopted two models. Model 1 was adjusted for age, sex, BMI, use of hypertension and sleeping medication, smoking and drinking habits, and depressive syndrome. Model 2 featured, along with the adjustments contained in Model 1, additional adjustments for physical activity and social relationship variables that were not used as independent variables in Model 1 because there was a significant correlation between PASE and LSNS scores $(r=0.266, P<0.001)$. Second, only Model 1 was used to examine the combined effect of physical activity and social relationships on sleep disorders. We calculated odds ratios (ORs) and 95\% confidence intervals (Cls). All analyses were performed using IBM SPSS Statistics version 26.0 (IBM Corp., Armonk, NY, USA).

\section{Results}

The mean age of the sample was $73.1 \pm 5.5$ years, and $56.3 \%$ of the participants were female. Individuals with sleep disorder accounted for $36.8 \%$ of the total sample. Table 1 shows the demographic characteristics of the four participant groups. The active group with a narrow range of social relationships featured a significantly lower ratio of females while the active group with a wide range of social relationships featured a significantly higher ratio of females than the other groups. Both active and inactive groups with a wide range of social relationships $(P<0.001)$ showed significantly lower GDS scores than the inactive group with a narrow range of social relationships. In addition, the active group with a wide range of social relationships showed a significantly lower GDS score than the active group with a narrow range of social relationships $(P<$ 0.001). Naturally, the LSNS and PASE scores significantly differed among the groups because of the participant group formation methods used. Notably, however, the active group with a wide range of social relationships had a significantly higher PASE score than the active group with a narrow range of social relationships $(P<0.001)$. 
Characteristics of participants

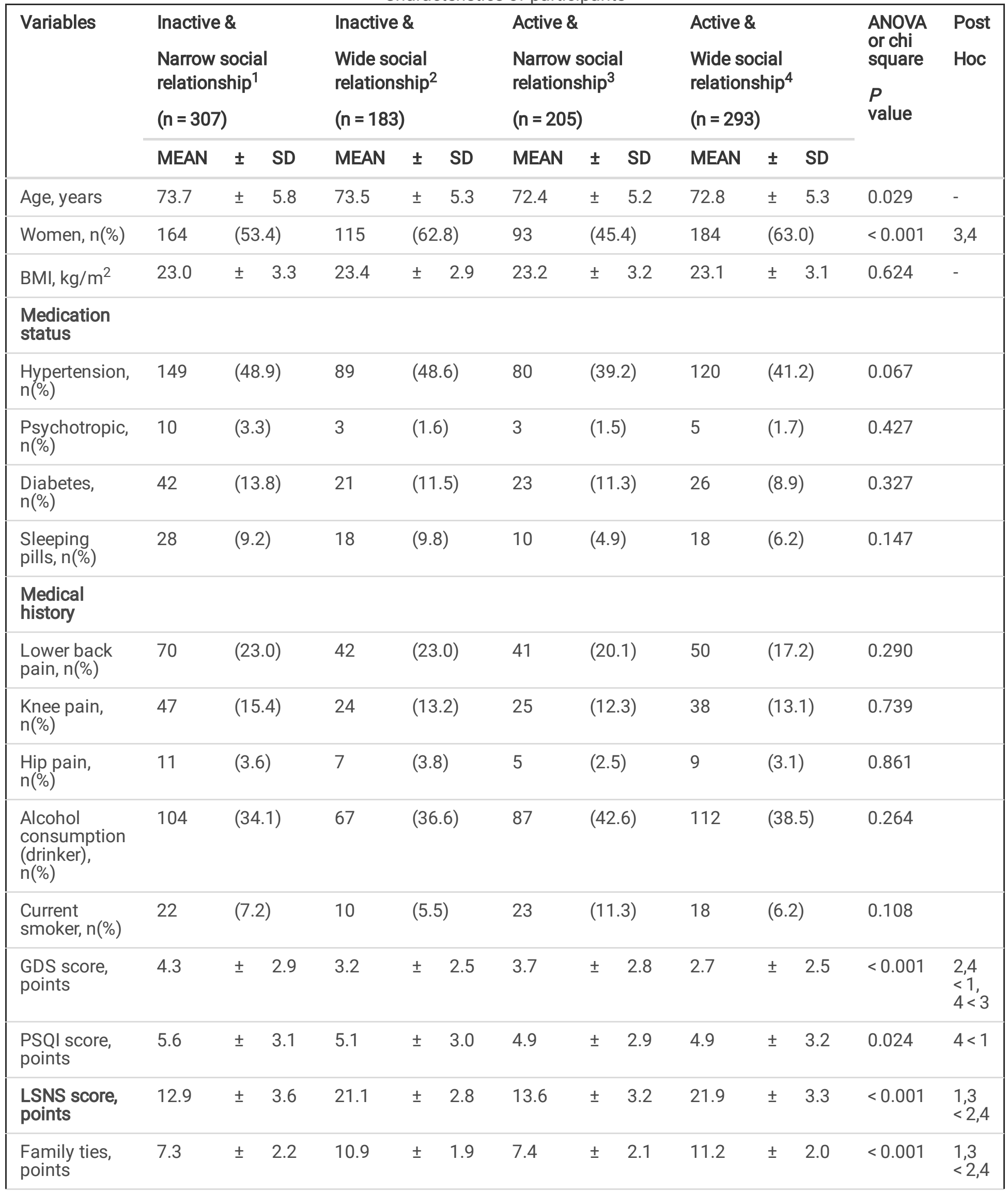

Note: SD, standard deviation; BMI, Body mass index; GDS, geriatric depression scale; LSNS, Lubben social network scale; PASE, physical activity scale for the elderly 


\begin{tabular}{|c|c|c|c|c|c|c|c|c|c|c|c|c|c|c|}
\hline \multirow[t]{4}{*}{ Variables } & \multirow{3}{*}{\multicolumn{3}{|c|}{$\begin{array}{l}\text { Inactive \& } \\
\text { Narrow social } \\
\text { relationship }{ }^{1} \\
(n=307)\end{array}$}} & \multirow{3}{*}{\multicolumn{3}{|c|}{$\begin{array}{l}\text { Inactive \& } \\
\text { Wide social } \\
\text { relationship } 2 \\
(n=183)\end{array}$}} & \multirow{3}{*}{\multicolumn{3}{|c|}{$\begin{array}{l}\text { Active \& } \\
\text { Narrow social } \\
\text { relationship } \\
(n=205)\end{array}$}} & \multirow{3}{*}{\multicolumn{3}{|c|}{$\begin{array}{l}\text { Active \& } \\
\text { Wide social } \\
\text { relationship } 4 \\
(n=293)\end{array}$}} & \multirow{4}{*}{$\begin{array}{l}\text { ANOVA } \\
\text { or chi } \\
\text { square } \\
P \\
\text { value }\end{array}$} & \multirow{4}{*}{$\begin{array}{l}\text { Post } \\
\text { Hoc }\end{array}$} \\
\hline & & & & & & & & & & & & & & \\
\hline & & & & & & & & & & & & & & \\
\hline & MEAN & \pm & SD & MEAN & \pm & SD & MEAN & \pm & SD & MEAN & \pm & SD & & \\
\hline $\begin{array}{l}\text { Friendship } \\
\text { ties, points }\end{array}$ & 5.7 & \pm & 2.8 & 10.2 & \pm & 1.9 & 6.2 & \pm & 2.5 & 10.7 & \pm & 2.2 & $<0.001$ & $\begin{array}{l}1,3 \\
<2,4\end{array}$ \\
\hline $\begin{array}{l}\text { PASE score, } \\
\text { points }\end{array}$ & 76.7 & \pm & 28.0 & 81.1 & \pm & 26.6 & 158.7 & \pm & 40.3 & 175.3 & \pm & 56.6 & $<0.001$ & $\begin{array}{l}1,2 \\
< \\
3,4 \\
3<4\end{array}$ \\
\hline $\begin{array}{l}\text { Leisure-time } \\
\text { physical } \\
\text { activity, } \\
\text { points }\end{array}$ & 13.5 & \pm & 13.8 & 14.9 & \pm & 13.7 & 28.3 & \pm & 24.7 & 32.9 & \pm & 30.8 & $<0.001$ & $\begin{array}{l}1,2 \\
<3,4\end{array}$ \\
\hline $\begin{array}{l}\text { Housework } \\
\text { physical } \\
\text { activity, } \\
\text { points }\end{array}$ & 60.6 & \pm & 27.9 & 64.7 & \pm & 27.8 & 102.8 & \pm & 30.8 & 109.2 & \pm & 32.6 & $<0.001$ & $\begin{array}{l}1,2 \\
<3,4\end{array}$ \\
\hline $\begin{array}{l}\text { Work-related } \\
\text { physical } \\
\text { activity, } \\
\text { points }\end{array}$ & 2.6 & \pm & 10.1 & 1.6 & \pm & 5.1 & 27.6 & \pm & 50.4 & 33.2 & \pm & 56.4 & $<0.001$ & $\begin{array}{l}1,2 \\
<3,4\end{array}$ \\
\hline $\begin{array}{l}\text { Note: SD, sta } \\
\text { PASE, physic }\end{array}$ & d devi & & $\begin{array}{l}\text { Ml, B } \\
\text { the }\end{array}$ & $\begin{array}{l}\text { mass } \\
\text { erly }\end{array}$ & & SDS, & iatric & & & ; LSNS & & & I netwo & cale; \\
\hline
\end{tabular}

Table 2 presents the effects of physical activity and social relationships on sleep disorder. In the unadjusted model and Model 1, both variables show linear trends regarding the prevalence of sleep disorder. However, the linear trends are significantly different in Model 2, which features adjustments for the other variable (i.e., physical activity or social relationships, depending on the variable being measured; Table 2). In Model 1, the unadjusted model, and Model 2, the prevalence of sleep disorder is significantly lower in the third tertile of both physical activity and social relationships than in the first tertile of the respective variable. 
Table 2

Association between physical activity, social relationship, and sleep disorder

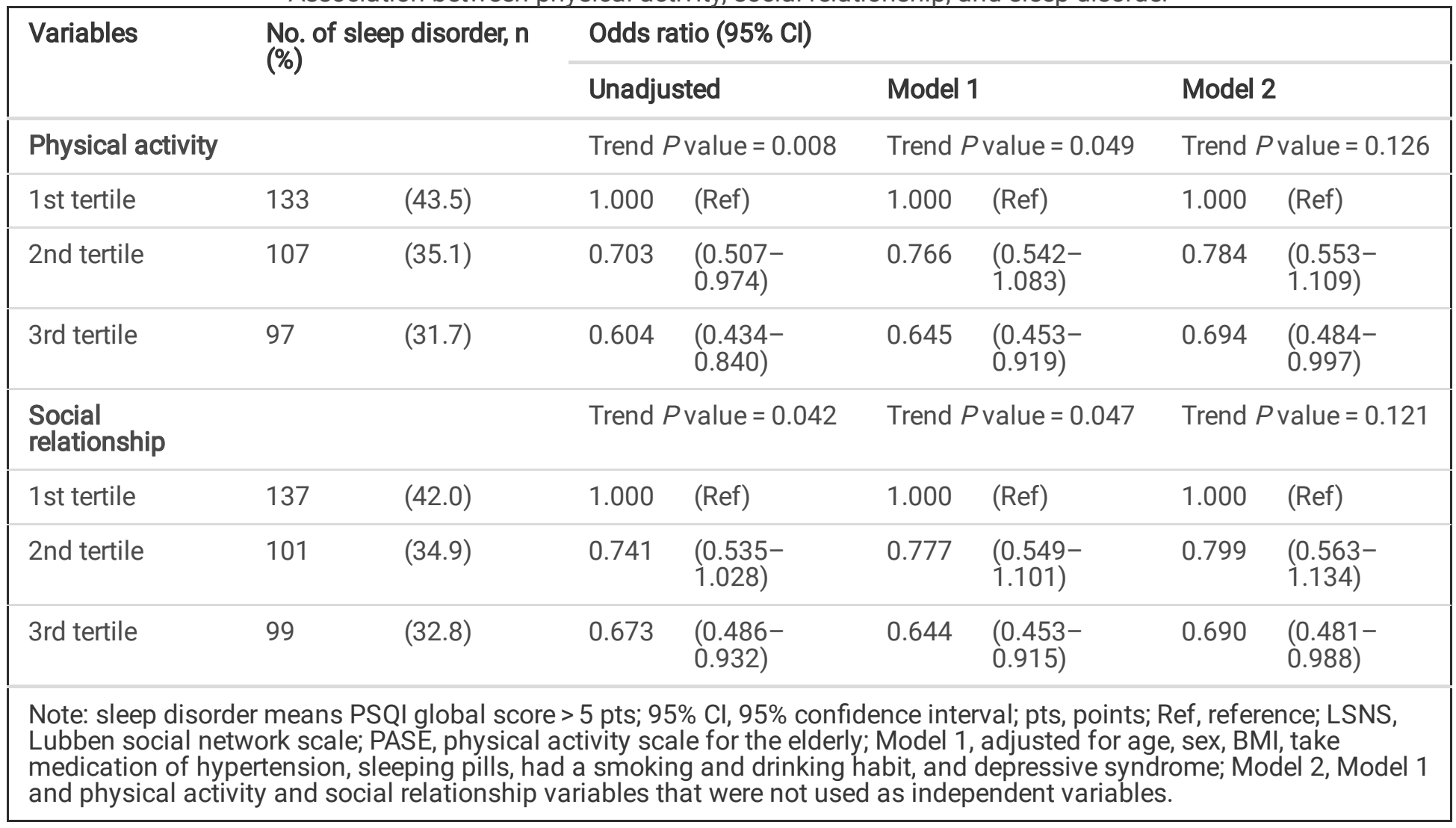

Table 3 shows the combined effect of physical activity and social relationships on sleep disorder. The only significant difference in Model 1 concerns the active group with a wide range of social relationships, which features a $41.5 \%$ lower prevalence of sleep disorder than the inactive group with a narrow range of social relationships. The other groups show no significant differences from the inactive group with a narrow range of social relationships (Table 3).

Table 3

Association between combined physical activity and social relationship, and sleep disorder

\begin{tabular}{|c|c|c|c|c|c|c|c|c|}
\hline \multirow[t]{2}{*}{ Variables } & & & \multirow{2}{*}{\multicolumn{2}{|c|}{$\begin{array}{l}\text { No. of sleep disorder, } n \\
(\%)\end{array}$}} & \multicolumn{4}{|c|}{ Odds ratio (95\% Cl) } \\
\hline & & & & & \multicolumn{2}{|c|}{ Unadjusted } & \multicolumn{2}{|c|}{ Model 1} \\
\hline Physical activity & & $\begin{array}{l}\text { Social } \\
\text { relationship }\end{array}$ & & & & & & \\
\hline $\begin{array}{l}\text { Inactive (0-115 } \\
\text { pts) }\end{array}$ & $\&$ & $\begin{array}{l}\text { Narrow }(2-17 \\
\text { pts) }\end{array}$ & 126 & $(44.1)$ & 1.000 & (Ref) & 1.000 & (Ref) \\
\hline $\begin{array}{l}\text { Inactive (0-115 } \\
\text { pts) }\end{array}$ & $\&$ & $\begin{array}{l}\text { Wide (18-30 } \\
\text { pts) }\end{array}$ & 61 & $(35.7)$ & 0.704 & $\begin{array}{l}(0.477- \\
1.040)\end{array}$ & 0.672 & $\begin{array}{l}(0.442- \\
1.022)\end{array}$ \\
\hline $\begin{array}{l}\text { Active (116-425 } \\
\text { pts) }\end{array}$ & \& & $\begin{array}{l}\text { Narrow }(1-17 \\
\text { pts) }\end{array}$ & 64 & (33.7) & 0.645 & $\begin{array}{l}(0.441- \\
0.944)\end{array}$ & 0.697 & $\begin{array}{l}(0.465- \\
1.043)\end{array}$ \\
\hline $\begin{array}{l}\text { Active (116-462 } \\
\text { pts) }\end{array}$ & $\&$ & $\begin{array}{l}\text { Wide (18-30 } \\
\text { pts) }\end{array}$ & 86 & (31.9) & 0.594 & $\begin{array}{l}(0.420- \\
0.839)\end{array}$ & 0.585 & $\begin{array}{l}(0.404- \\
0.847)\end{array}$ \\
\hline
\end{tabular}

\section{Discussion}


This study examined sleep disorder in older adults in terms of its association with daily physical activity and social relationships, both individually and in combination with each other. Our study showed that a high level of physical activity and a wide range of social relationships may, independently of each other, positively affect sleep quality (Table 2). This result is similar to previous findings that low levels of physical activity and narrow ranges of social relationships are related to poor sleep quality in older adults [9,20]; it should be noted that, unlike these previous studies, we adjusted for the effect of one variable when measuring the other. However, the prevalence of sleep disorder was significantly lower only in the active group with a wide range of social relationships, which featured high levels of both variables, compared to the inactive group with a narrow range of social relationships (Table 3). These results do not support our hypothesis that high levels of one variable with low levels of the other (e.g., inactive people with a wide range of social relationships) results in a lower prevalence of sleep disorder than low activity levels and a narrow range of social relationships.

Sleep disorder and depressive syndrome are strongly linked [31], and the rates of both of these are significantly higher in older adults than in younger people [32]. Overall, $83 \%$ of patients with depression have experienced some form of sleep disturbance [31] and, although the effects of daily sleep quality on next-day mood are larger than the effects of daily mood on sleep quality, sleep quality and mood share a bilateral relationship [33]. Some previous studies have shown that strategies for regulating mood control can improve sleep quality [34]. In this study, although no significant differences were observed, the groups with low levels on one variable (i.e., the inactive group with a wide range of social relationships and the active group with a narrow range of social relationships) showed 14-26\% lower depressive syndrome scores (i.e., GDS score; Table 1) than the inactive group with a narrow range of social relationships. Meanwhile, the active group with a wide range of social relationships showed a significantly lower value than the inactive group with a narrow range of social relationships ( $37 \%$ lower) and the active group with a narrow range of social relationships (27\% lower). The significant difference in sleep disorder between the inactive group with a narrow range of social relationships and the active group with a narrow range of social relationships disappeared after full adjustment for covariates, including depressive syndrome. However, the difference between the inactive group with a narrow range of social relationships and the active group with a wide range of social relationships remained significant (Table 3).

Researchers have highlighted several potential mechanisms by which physical activity affects sleep quality, including energy conservation, increases body and central nervous system temperatures, and reduces anxiety [35-37]. Meanwhile, the effects of social relationships on sleep quality are not fully understood. Theoretically, however, strong social relationships provide an evolutionarily adaptive function, creating a safe environment in which sleeping persons feel they are protected by others from dangers (e.g., in an evolutionary context, predators and enemies) [20]. Recent studies have also hypothesized that social isolation causes chronic stress [17], directly affects anxiety, and decreases sleep satisfaction [20, 21]. Social isolation is related to lower physiological functioning and higher risks of physical disorders [17]. In particular, addressing deficits in terms of social relationships and physiological activity may directly arrest early progression toward chronic diseases, and could also delay disease onset and lessen disease burden in later life [17]. The above findings suggest that physical activity and social relationships produce overlapping, synergistic anti-anxiety and anti-depressant effects.

In a previous study, the present authors revealed that communal exercise has a lower hazard ratio for five-year morality than no exercise [38]. The present study suggests that physical activity and exercising with others [39, 40] may have a synergistic effect on not only physical functions but also mental health and sleep quality in older adults.

A previous epidemiological study showed that intellectual, social, and recreational activities are correlated with cognitive function [23]. Indeed, an experimental study revealed that low-intensity exercise with social interaction not only has positive effects on sleep quality but also improves cognitive function, particularly attention ability, in older adults [22]. It has been postulated that exposure to social relationships and engaging in physical activity increase blood flow to the brain, improving neuronal function and facilitating deep sleep $[22,23]$. We suggest that future studies should examine whether the effects of physical activity and social interaction on older adults' sleep quality are mediated by improved cognitive function; methods such as polysomnography and functional near-infrared spectroscopy could be used to perform this examination. 
Our study has several limitations. First, although this study examined the lower prevalence of sleep disorder among individuals who are active and have a wide range of social relationships (i.e., lacking in neither variable), we could not explain the causal relationship because of the cross-sectional study design applied. Thus, this aspect warrants further investigation through a prospective cohort research or an intervention study, for example. Second, we did not examine whether supportive and aversive social relationships have different effects on sleep disorder. In this study, we only focused on supportive relationships because a previous study revealed no significant association between aversive relationships and sleep quality [20]. Nevertheless, further studies should consider adverse relationships in this regard. Third, all of the variables were assessed using self-report scales; thus, our findings may have been influenced by recall and reporting bias. Fourth, physical activity and social relationship factors may be influenced by individual differences. Thus, future studies should consider gender differences and implement stratification in terms of physical function and the presence of depressive syndrome. Finally, although a previous epidemiological study involving a Japanese population [1] reported the same prevalence of sleep disorder (36.2\%) as in the present study, the generalizability of our results is uncertain because of the small sample size.

\section{Conclusions}

In conclusion, high levels of physical activity and social relationships are independently related to good sleep quality. However, low levels of either variable (i.e., inactive with a wide range of social relationships or active with a narrow range of social relationships) results in a non-significant relationship with sleep quality. Thus, these results suggest the importance of considering both physical activity and social relationships when seeking to improve sleep quality among older adults.

\section{Declarations}

\section{Ethics approval and consent to participate}

This study was conducted in accordance with the guidelines of the Declaration of Helsinki. The study concepts were explained to all participants prior to commencement, and all participants provided written informed consent. The ethics committee of the University of Tsukuba approved this study (ref no. Tai 30-5).

\section{Consent for publication}

Not applicable

\section{Availability of data and materials}

The datasets used and/or analysed during the current study are available from the corresponding author on reasonable request.

\section{Funding}

This work was supported by the JST-Mirai Program (grant number: JPMJMI19D8), JSPS KAKENHI (grant number: JP20K23250), the COI STREAM launched in 2013 by the Ministry of Education, Culture, Sports, Science and Technology

(MEXT), the COI-NEXT (grant number: JPMJPF2017) launched in 2020 by the MEXT, and the Univers Foundation, Japan. The sponsors played no role in the preparation of data of the manuscript.

\section{Authors' contributions}

Conceptualization: J.S.; methodology: J.S., J.L., and K.N.; formal analysis: J.S., Y.F., K.J., K.T., J.L., and T.I.; investigation: J.S., and T.O.; writing of the manuscript: J.S., J.L., and K.N.

\section{Acknowledgements}


We would like to thank the study participants, the laboratory seniors who set up the research in Kasama City, and Kasama City officials for their cooperation. In addition, the authors would like to thank Editage (www.editage.jp) for English-language editing.

\section{References}

1. Hishikawa N, Fukui Y, Sato K, Ohta Y, Yamashita T, Abe K. Cognitive and affective functions associated with insomnia: a population-based study. Neurol Res. 2017 Apr;39(4):331-336. doi:10.1080/01616412.2017.1281200

2. Patel D, Steinberg J, Patel P. Insomnia in the Elderly: A Review. J Clin Sleep Med. 2018 Jun 15;14(6):1017-1024. doi:10.5664/jcsm.7172

3. Stepnowsky CJ, Ancoli-Israel S. Sleep and Its Disorders in Seniors. Sleep Med Clin. 2008 Jan;3(2):281-293. doi:10.1016/j.jsmc.2008.01.011

4. Kripke DF, Garfinkel L, Wingard DL, Klauber MR, Marler MR. Mortality associated with sleep duration and insomnia. Arch Gen Psychiatry. 2002 Feb;59(2):131-136. doi:10.1001/archpsyc.59.2.131

5. Stone KL, Ancoli-Israel S, Blackwell T, Ensrud KE, Cauley JA, Redline S, et al. Actigraphy-measured sleep characteristics and risk of falls in older women. Arch Intern Med. 2008 Sep 8;168(16):1768-1775. doi:10.1001/archinte.168.16.1768

6. Yaffe K, Falvey CM, Hoang T. Connections between sleep and cognition in older adults. Lancet Neurol. 2014 Oct;13(10):1017-1028. doi:10.1016/S1474-4422(14)70172-3

7. Okajima I, Komada Y, Nomura T, Nakashima K, Inoue Y. Insomnia as a risk for depression: a longitudinal epidemiologic study on a Japanese rural cohort. J Clin Psychiatry. 2012 Mar;73(3):377-383. doi:10.4088/JCP.10m06286

8. By the 2019 American Geriatrics Society Beers Criteria ${ }^{\circledR}$ Update Expert Panel. American Geriatrics Society 2019 Updated AGS Beers Criteria ${ }^{\circledR}$ for Potentially Inappropriate Medication Use in Older Adults. J Am Geriatr Soc. 2019 Apr;67(4):674694. doi:10.1111/jgs. 15767

9. Holfeld B, Ruthig JC. A longitudinal examination of sleep quality and physical activity in older adults. J Appl Gerontol. 2014 Oct;33(7):791-807. doi:10.1177/0733464812455097

10. Seol J, Fujii Y, Inoue T, Kitano N, Tsunoda K, Okura T. Effects of Morning Versus Evening Home-Based Exercise on Subjective and Objective Sleep Parameters in Older Adults: A Randomized Controlled Trial. J Geriatr Psychiatry Neurol. 2020 May 20;891988720924709, Online ahead of print. doi:10.1177/0891988720924709

11. Dolezal BA, Neufeld EV, Boland DM, Martin JL, Cooper CB. Interrelationship between Sleep and Exercise: A Systematic Review. Adv Prev Med. 2017;2017:1364387. doi:10.1155/2017/1364387

12. Zheng B, Yu C, Lin L, Du H, Lv J, Guo Y, et al. Associations of domain-specific physical activities with insomnia symptoms among 0.5 million Chinese adults. J Sleep Res. 2017 Jun; 26(3): 330-337. doi:10.1111/jsr.12507

13. Li J, Yang B, Varrasse M, Ji X, Wu M, Li M, et al. Physical Activity in Relation to Sleep Among Community-Dwelling Older Adults in China. J Aging Phys Act. 2018 Oct;26(4):647-654. doi:10.1123/japa.2017-0270

14. Irwin MR, Olmstead R, Motivala SJ. Improving sleep quality in older adults with moderate sleep complaints: A randomized controlled trial of Tai Chi Chih. Sleep. 2008 Jul 1;31(7): 1001-1008.

15. Dam TT, Ewing S, Ancoli-Israel S, Ensrud K, Redline S, Stone K, et al. Association between sleep and physical function in older men: the osteoporotic fractures in men sleep study. J Am Geriatr Soc. 2008 Sep;56(9):1665-1673. doi:10.1111/j.1532-5415.2008.01846.x

16. Buman MP, Hekler EB, Bliwise DL, King AC. Moderators and mediators of exercise-induced objective sleep improvements in midlife and older adults with sleep complaints. Health Psychol. 2011 Sep;30(5):579-587. doi:10.1037/a0024293

17. Yang YC, Boen C, Gerken K, Li T, Schorpp K, Harris KM. Social relationships and physiological determinants of longevity across the human life span. Proc Natl Acad Sci U S A. 2016 Jan 19;113(3):578-83. doi:10.1073/pnas.1511085112

18. Holt-Lunstad J, Smith TB, Layton JB. Social relationships and mortality risk: a meta-analytic review. PLoS Med. 2010 Jul 27;7(7):e1000316. doi:10.1371/journal.pmed.1000316

Page $10 / 12$ 
19. Marmot MG. Status syndrome: a challenge to medicine. JAMA. 2006 Mar 15;295(11):1304-1307. doi:10.1001/jama.295.11.1304

20. Kent RG, Uchino BN, Cribbet MR, Bowen K, Smith TW. Social Relationships and Sleep Quality. Ann Behav Med. 2015 Dec;49(6):912-917. doi:10.1007/s12160-015-9711-6

21. Stafford M, Bendayan R, Tymoszuk U, Kuh D. Social support from the closest person and sleep quality in later life: Evidence from a British birth cohort study. J Psychosom Res. 2017 Jul;98:1-9. doi:10.1016/j.jpsychores.2017.04.014

22. Naylor E, Penev PD, Orbeta L, Janssen I, Ortiz R, Colecchia EF, et al. Daily social and physical activity increases slowwave sleep and daytime neuropsychological performance in the elderly. Sleep. 2000 Feb 1;23(1):87-95

23. Su X, Huang $X$, Jin $Y$, Wan S, Han Z. The relationship of individual social activity and cognitive function of community Chinese elderly: a cross-sectional study. Neuropsychiatr Dis Treat. 2018 Aug 24;14:2149-2157. doi:10.2147/NDT.S160036

24. Okura T, Tsuji T, Tsunoda K, Kitano N, Yoon JY, Saghazadeh M, et al. Study protocol and overview of the Kasama Study: Creating a comprehensive, community-based system for preventive nursing care and supporting successful aging. The Journal of Physical Fitness and Sports Medicine. 2017 Jan;6(1):49-57. doi: 10.7600/.jpfsm.6.49

25. Washburn RA, Smith KW, Jette AM, Janney CA. The Physical Activity Scale for the Elderly (PASE): development and evaluation. J Clin Epidemiol. 1993 Feb;46(2):153-162. doi:10.1016/0895-4356(93)90053-4

26. Lubben J, Blozik E, Gillmann G, lliffe S, von Renteln Kruse W, et al. Performance of an abbreviated version of the Lubben Social Network Scale among three European community-dwelling older adult populations. Gerontologist. 2008 Dec 15;4(6):563-571. doi:10.1093/geront/46.4.503

27. Buysse DJ, Hall ML, Strollo PJ, Kamarck TW, Owens J, Lee L, et al. Relationships between the Pittsburgh Sleep Quality Index (PSQI), Epworth Sleepiness Scale (ESS), and clinical/polysomnographic measures in a community sample. J Clin Sleep Med. 2008 Dec 15;4(6):563-571.

28. Ancoli-Israel S. Sleep and aging: prevalence of disturbed sleep and treatment considerations in older adults. J Clin Psychiatry. 2005;66 Suppl 9:24-30; quiz 42-3.

29. Herrmann N, Mittmann N, Silver IL, Shulman KI, Busto UA, Shear NH, et al. A validation study of The Geriatric Depression Scale short form. Int J Geriatr Psychiatry. 1996 May;11:457-460. doi: 10.1002/(SICI)1099-1166(199605)11:5<457::AIDGPS325>3.0.C0;2-2

30. Kitano N, Tsunoda K, Tsuji T, Osuka Y, Jindo T, Tanaka K, et al. Association between difficulty initiating sleep in older adults and the combination of leisure-time physical activity and consumption of milk and milk products: a crosssectional study. BMC Geriatr. 2014 Nov 18;14:118. doi:10.1186/1471-2318-14-118

31. Nutt D, Wilson S, Paterson L. Sleep disorders as core symptoms of depression. Dialogues Clin Neurosci. 2008 Sep;10(3):329-336. doi: 10.31887/DCNS.2008.10.3/dnutt

32. Stewart R, Besset A, Bebbington P, Brugha T, Lindesay J, Jenkins R, et al. Insomnia comorbidity and impact and hypnotic use by age group in a national survey population aged 16 to 74 years. Sleep. 2006 Nov;29(11):1391-7. doi: 10.1093/sleep/29.11.1391.

33. Triantafillou S, Saeb S, Lattie EG, Mohr DC, Kording KP. Relationship Between Sleep Quality and Mood: Ecological Momentary Assessment Study. JMIR Ment Health. 2019 Mar 27;6(3):e12613. doi:10.2196/12613

34. Hoge EA, Bui E, Marques L, Metcalf CA, Morris LK, Robinaugh DJ, et al. Randomized controlled trial of mindfulness meditation for generalized anxiety disorder: effects on anxiety and stress reactivity. J Clin Psychiatry. 2013 Aug;74(8):786-792. doi:10.4088/JCP.12m08083

35. St-Onge MP. The role of sleep duration in the regulation of energy balance: effects on energy intakes and expenditure. $J$ Clin Sleep Med. 2013 Jan 15;9(1):73-80. doi:10.5664/jcsm.2348

36. Driver HS, Taylor SR. Exercise and sleep. Sleep Med Rev. 2000 Aug;4(4):387-402. doi:10.1053/smrv.2000.0110 
37. Taylor AH, Cable NT, Faulkner G, Hillsdon M, Narici M, Van Der Bij AK. Physical activity and older adults: a review of health benefits and the effectiveness of interventions. J Sports Sci. 2004 Aug;22(8):703-725.

doi:10.1080/02640410410001712421

38. Fujii Y, Fujii K, Jindo T, Kitano N, Seol J, Tsunoda K, et al. Effect of Exercising with Others on Incident Functional Disability and All-Cause Mortality in Community-Dwelling Older Adults: A Five-Year Follow-Up Survey. Int J Environ Res Public Health. 2020 Jun 17;17(12):4329. doi:10.3390/ijerph17124329

39. Östh J, Diwan V, Jirwe M, Diwan V, Choudhary A, Mahadik VK, et al. Effects of yoga on well-being and healthy ageing: study protocol for a randomised controlled trial (FitForAge). BMJ Open. 2019 May 29;9(5):e027386. doi:10.1136/bmjopen-2018-027386

40. Pereira JR, Gobbi S, Teixeira CVL, Naschimento CMC, Corazza DI, Vital TM, et al. Effects of Square-Stepping Exercise on balance and depressive symptoms in older adults. Motriz: Revista de Educação Física. 2014 Oct/Dec;20(4):454-460. doi:10.1590/S1980-65742014000400013 